\title{
Predicting Job Satisfaction: Contributions of Individual Gratitude and Institutionalized Gratitude
}

\author{
Lea Waters \\ Melbourne Graduate School of Education, University of Melbourne, Melbourne, Australia \\ Email: l.waters@unimelb.edu.au
}

Received September 14 ${ }^{\text {th }}$, 2012; revised October 15 ${ }^{\text {th }}$, 2012; accepted November $7^{\text {th }}, 2012$

\begin{abstract}
This study examined the role that employee perceptions of dispositional gratitude, state gratitude and institutionalized gratitude had upon job satisfaction. Employees $(n=171)$ completed measures of dispositional, state and institutionalized gratitude together with job satisfaction. Multiple Hierarchical Regression showed that state gratitude and institutional gratitude uniquely predict job satisfaction. The results have implications for the fields of positive organizational scholarship and positive organizational behavior and suggest that workplaces aiming to increase job satisfaction can do so through organizationally-based gratitude interventions and by institutionalizing gratitude into workplace culture.
\end{abstract}

Keywords: Positive Psychology; Gratitude; Job Satisfaction; Positive Organizational Behavior

\section{Introduction}

Gratitude is a universal human virtue (Emmons, 2003, 2007) that has been defined by Howell (2007) as "the active and conscious practice of giving thanks” (p. 12). The pioneering work of Emmons and McCullough has legitimized gratitude as an important topic for scientific inquiry (Emmons, 2003; 2007; Emmons \& McCullough, 2003; McCullough, Emmons, \& Tsang, 2002). Wood, Froh and Geraghty (2010) argue that gratitude interventions are amongst the most successful of all positive psychology interventions in promoting wellbeing.

The science of gratitude has typically focused on individual gratitude, that is, gratitude which is either dispositional or state-like (Wood et al., 2010). Research shows that wellbeing is influenced by one's stable disposition towards gratitude and by state gratitude that can be triggered/heightened through a gratitude intervention (GI) (e.g., gratitude letter, gratitude lists). Wood et al.'s (2010) review shows that much research has been done to explore the link between gratitude and well-being (e.g., life satisfaction, mood, self-esteem) as well as gratitude and social relationships (e.g., helping behavior, pro-social motivation). However, limited consideration has been given to the role of gratitude in an organizational context and the influence of gratitude on indicators of work well-being such as job satisfaction. In 2003 Emmons argued that "there is virtually no hard evidence on gratitude in organizations” (p. 84). This argument remains valid nine years on.

Presumably the link between gratitude and positive outcomes remains present in a workplace context. The causal mechanisms that link gratitude to well-being such as the broaden and build process, the gratitude-coping link and the grateful schema (Emmons \& Anjali, 2011) are all likely to operate within the workplace and are, thus, likely to link dispositional gratitude with indicators of wellbeing. To date, there has only been two published studies linking dispositional gratitude of employees to work wellbeing. Andersson, Giacalone and Jurkiewicz (2007) found a positive relationship between gratitude and corporate social responsibility in a sample of white-collar employees.
Chan (2010) found an inverse relationship between dispositional gratitude and workplace burnout in teachers.

The link between gratitude and job satisfaction has not been empirically tested. This gap is surprising given that job satisfaction is a long standing and well accepted measure of wellbeing at work (Muchinsky, 2003). Indeed, Fisher's (2010) recent review of employee happiness posited job satisfaction as one of the three top indicators of wellbeing at work. Job satisfaction is defined as "the degree of pleasure an employee derives from his or her job” (Muchinsky, 2003: p. 307) and is aligned with a positive psychology approach.

Beyond the influence of dispositional and state gratitude upon job satisfaction, the degree to which a workplace culture expresses and reinforces gratitude is also likely to influence job satisfaction. Cameron's (2012) research can be used to suggest that workplaces which enable virtuous behaviors, such as gratitude, will foster employee wellbeing. Institutionalized gratitude (Cameron, 2012) is defined in the present study as "gratitude that is culturally embedded within the organization, through its people, policies and practices, such that thankfulness and appreciation are customary features of daily work life".

Using Cameron et al.’s (2011) organizational virtuousness model, institutionalized gratitude can be said to be enacted in and through the organization. Gratitude enacted in organizations is done so by members giving thanks to each other. Research by Bennett, Ross and Sunderland (1996) found that when patients and managers provided gratitude and recognition to employees who worked in carer roles for HIV/AIDS patients, it buffered the employees from burnout. Gratitude fostered through organizations is done so by the features and practices of the organization that legitimize gratitude. For example, Emmons (2003) highlights Appreciate Inquiry as an organizational method that can build gratitude.

Institutionalized gratitude is not simply the aggregate of individuals who express gratitude in the workplace, rather, it is conceptualized in this paper as a distinctive and enduring organizational characteristic that promotes gratitude within and 
between organizational members across time. Thus, institutionalized gratitude may have a unique effect on job satisfaction above and beyond the effect of dispositional gratitude because institutionalized gratitude comes from outside of the individual. In addition, institutionalized gratitude may have a unique effect on job satisfaction above and beyond the effect of state gratitude because institutionalized gratitude is enduring rather than transient. The intra-personal processes that link dispositional and state gratitude to job satisfaction are likely to be the cognitive and emotional mechanisms listed above such as the broaden and build process, the gratitude-coping link and the grateful schema (Wood et al., 2010). In contrast, the link between institu- tional gratitude and job satisfaction will come through social processes and group dynamics like the contagion effect, recip- rocal altruism, the elevation effect and the amplification effect (Cameron, Bright, \& Caza, 2004; Emmons, 2003; Frederickson, 2003). Thus, an employee may not feel gratitude themselves, but will still experience improvements in job satisfaction through the positive influence of a grateful culture.

The current study adds to the gratitude literature in two important ways: 1) it empirically tests the relationship between dispositional and state gratitude with job satisfaction, and 2) it examines the relationship between employee perception of institutional gratitude and job satisfaction.

Hypothesis 1: Dispositional gratitude and state gratitude will be significantly related to job satisfaction.

Hypothesis 2: Institutional gratitude will have significant predictive variance upon job satisfaction above dispositional gratitude and state gratitude.

\section{Method}

\section{Sample and Measures}

One hundred and seventy one employees (45\% male) across two different sectors (teaching and finance) participated. Average tenure with current organization was $7.18(\mathrm{SD}=4.75)$ years, $82 \%$ were university educated and the average age was 41.16 $(\mathrm{SD}=8.88)$ years.

Four measures were used in the following order of assessment: 1) The Index of Job Satisfaction (IS) (Brayfield \& Rothe, 1951) assesses subjective perspectives on work (e.g., "I find real enjoyment in my job”; 6 items, $\alpha=.68$ ); 2) The integrity and gratitude sub-scale of the Positive Practices Scale (IG-PPS) (Cameron et al., 2004) assesses employee perceptions of the degree to which their workplace fosters a culture characterized by gratitude and integrity (e.g., "At my workplace, we express gratitude to each other; 7 items, $\alpha=.92)$; 3) The Gratitude Questionnaire (GQ-6) (McCullough, et al., 2002) assesses dispositional, stable, tendencies to experience gratitude in daily life (e.g., "I have so much in life to be thankful for"; 6 items, $\alpha$ =.74); and 4) The Gratitude, Adjective Checklist (GAC) (McCullough et al., 2002) was used to assess state gratitude. Employees were asked to think about their feelings over the past week at work and respond to the three items that assess gratefulness, thankfulness, and appreciativeness (3 items; $\alpha$ $=.74$ ). All scales were answered along a five point Likert scale ( $1=$ not at all, $5=$ very much). All scales are well-validated, and have been used across multiple samples.

\section{Procedure}

Participants were recruited through a series of professional development workshops on positive psychology run by the researcher. The researcher was invited to three schools and two investment banking companies to run these workshops. Prior to commencing the workshop, participants completed the IJS, IG-PPS, GQ-6 and GAC.

\section{Results}

Table 1 presents the means, standard deviations and correlation coefficients. Job satisfaction was significantly correlated with dispositional gratitude, state gratitude and institutional gratitude. A hierarchical multiple regression was conducted using SPSS in which the demographic measures (age, length of tenure, profession and gender) were entered before dispositional gratitude (step 2), state gratitude (step 3) and institutional gratitude (step 4). The overall model was significant, $F(7,156)$ $=7.35, p<.001$, and $24.8 \%$ of the variance in job satisfaction was predicted. The variance in job satisfaction scores accounted for by demographic factors was not significantly different from zero. However, there were statistically significant increases in variance when dispositional gratitude $(\mathrm{F}(1,158)=16.63, p$ $<.000)$, state gratitude $(\mathrm{F}(1,157)=23.76, p<.000)$ and institutional gratitude $(\mathrm{F}(1,156)=5.83, p<.05)$ were subsequently entered into the equation. Specifically, they accounted for $9.5 \%$, $11.8 \%$ and $2.8 \%$ of variability in job satisfaction above those of previous predictor variables. Interestingly, Dispositional gratitude did not significantly contribute to the model after accounting for state gratitude scores.

\section{Discussion}

This preliminary study responds to calls by Emmons (2003) and Cameron et al., (2011) to conduct scholarly research on virtuousness in organizations. All three types of gratitude were positively correlated with job satisfaction. However, dispositional gratitude was not a significant predictor of job satisfaction when state gratitude and institutionalized gratitude were entered into the regression. This may be because state gratitude and institutionalized gratitude were assessed as more localized constructs anchored within a work context and as such, they had more of a proximal nature to an employee's assessment of

Table 1.

Means, standard deviations and correlation coefficients for the study variables.

\begin{tabular}{ccccccc}
\hline & Mean (SD) & JS & Age & CT & DG & SG \\
\hline $\begin{array}{c}\text { Job } \\
\text { Satisfaction } \\
\text { (JS) } \\
\text { Age }\end{array}$ & $5.92(.78)$ & & & & & \\
$\begin{array}{c}\text { Current tenure } \\
\text { (CT) }\end{array}$ & $71.16(8.88)$ & -.01 & & & & \\
$\begin{array}{c}\text { Dispositional } \\
\text { Gratitude } \\
\text { (DG) }\end{array}$ & $5.56(.78)$ & $.29^{* *}$ & -.04 & .09 & & \\
$\quad \begin{array}{c}\text { State } \\
\text { Gratitude (SG) } \\
\text { Institutional } \\
\text { Gratitude }\end{array}$ & $5.93(.76)$ & $.45^{* *}$ & -.03 & -.02 & $.44^{* *}$ & \\
\hline
\end{tabular}

Note: $\mathrm{n}=164 ;{ }^{* *}$ Correlation is significant at the 0.01 level (2-tailed); ${ }^{*}$ Correlation is significant at the 0.05 level (2-tailed). 
the degree to which they derive pleasure from work, thus minimizing the role of dispositional gratitude.

The significant relationship between state gratitude and job satisfaction suggests that organizational leaders can aim to boost job satisfaction by regularly prompting grateful emotions. There is convincing evidence to show gratitude interventions promote wellbeing in many different samples and settings (Wood et al., 2010). However, little work has been done on organizationally-based gratitude interventions (OBGI). In Chan's (2010) research, employees who used a weekly gratitude list together with the Naiken meditation questions for an eight-week GI reported improvements in life satisfaction and positive affect. However, the employees engaged in the GI in their homes rather than at work. Howell (2012) established a year-long OBGI with teachers from two schools who formed a gratitude group and met each week in the staffroom to explore gratitude. Her qualitative research found that teachers in this OBGI reported enhanced wellbeing and relationships. To date, these are the only two published studies on OBGI's.

However, leaders can transfer many of the existing GI's (see Wood et al., 2010) into a workplace context. Further ideas include gratitude boards in the staffroom, providing employees with thank-you postcards to send home to their colleagues, gratitude lists included in weekly meetings, gratitude awards and other activities that are designed to orient employees to appreciate what is good in their workplace and express gratitude to colleagues.

The results also suggest that employees gain benefit, in the form of greater job satisfaction, through belonging to a workplace culture that endorses gratitude. This benefit operates above and beyond the amount of gratitude an employee feels within him/herself. Through the contagion and elevation effects, the expression of gratitude is amplified across an organization and reciprocally expanded, which has the potential to positively influence job satisfaction of all employees (Emmons, 2003). Leaders can seek to institutionalize gratitude through role modelling practices such as publicly expressing gratitude in team meetings and staff assemblies, through company reward policies, appreciative inquiry methods, and by creating thankful relationships amongst employees. Beyond these behavioral manifestations of gratitude, those leaders who adopt a deeper life orientation of appreciation and move away from a deficit, or complaint focus will be the leaders who truly inspire a culture of gratitude (Howell, 2012; Emmons, 2007).

Several methodological considerations are present in this study. All measures were self-report which can lead to common source bias. The study accessed employees from two sectors, but a wider range of professions is needed in order to generalize the results. Also, it is possible that there is a selection bias in the sample, as the five workplaces that invited the researcher to conduct the positive psychology training are, presumably, organizations that are receptive to promoting positive cultures, which may mean that the effect of gratitude upon wellbeing was stronger in the sample. Finally, the study was cross sectional and cannot be used to draw conclusions about the relationships between gratitude and job satisfaction over time. The influence of disposition may be stronger over time than at one testing point.

In their foundational paper launching the field of positive psychology, Seligman and Csikszentmihlyi (2000) contended that the application of positive psychology can be used to create "positive institutions" (p. 5). The relationship between institutionalized gratitude and job satisfaction is a fruitful area for future research towards this valuable purpose.

\section{REFERENCES}

Andersson, L. M., Giacalone, R. A., \& Jurkiewicz, C. L. (2007). On the relationship of hope and gratitude to corporate social responsibility. Journal of Business Ethics, 70, 401-409.

doi:10.1007/s10551-006-9118-1

Bennett, L., Ross, M. W., \& Sunderland, R. (1996). The relationship between recognition, rewards and burnout in aids caring. Aids Care-Psychological and Socio-Medical Aspects of Aids/HIV, 8, 145153.

Brayfield, A. H., \& Rothe, H. F. (1951). An index of job satisfaction. Journal of Applied Psychology, 35, 307-311. doi:10.1037/h0055617

Cameron, K. (2012). Effects of virtuous leadership of organizational performance. In S. I. Donaldson, M. Csikszentmihlyi., \& J. Nakamura (Eds.), Applied positive psychology: Improving everyday life, health, schools, work and Society (pp. 171-183). East Sussex: Routledge

Cameron, K., Bright, D., \& Caza, A. (2004). Exploring the relationships between organizational virtuousness and performance. American Behavioral Scientist, 4, 766-790. doi:10.1177/0002764203260209

Cameron, K., Mora, C., Leutscher, L., \& Calarco, M. (2011). Effects of positive practices on organizational effectiveness. Journal of Applied Behavioral Science, 47, 266-308. doi:10.1177/0021886310395514

Chan, D. (2010). Gratitude, gratitude intervention and subjective wellbeing among Chinese school teachers in Hong Kong. Educational Psychology, 30, 139-153. doi:10.1080/01443410903493934

Emmons, R. (2003). Acts of gratitude in organizations. In K. S. Cameron, J. E. Dutton, \& R. E. Quinn (Eds.), Positive organizational scholarship (pp. 81-93). San Francisco, CA: Berrett-Koehler.

Emmons, R. A. (2007). Thanks! How the new science of gratitude can make you happier. New York: Houghton-Mifflin.

Emmons, R., \& Anjali, M. (2011). Why gratitude enhances well- being: What we know, what we need to know. In M. Kennon, T. Sheldon, T. Kashdan, \& M. F. Steger (Eds), Designing positive psychology: Taking stock and moving forward (pp. 248-264). New York: Oxford Press.

Emmons , R. A., \& McCullough , M. E. (2003). Counting blessings versus burdens: An experimental investigation of gratitude and subjective well-being in daily life. Journal of Personality and Social Psychology, 84, 377-389. doi:10.1037/0022-3514.84.2.377

Fredrickson, B. L. (2003). Positive emotions and upward spirals in organizations. In K. S. Cameron, J. E. Dutton, \& R. E. Quinn (Eds.), Positive organizational scholarship: Foundations of a new discipline (pp. 163-175). San Francisco, CA: Berrett-Koehler.

Fisher, C. (2010). Happiness at work. International Journal of Management Reviews, 12, 384-412. doi:10.1111/j.1468-2370.2009.00270.x

Howell, K. (2012). Gratitude in education: A radical view. Rotterdam: Sense Publishers. doi:10.1007/978-94-6091-814-8

McCullough, M. E., Emmons, R. A., \& Tsang, J. A. (2002). The grateful disposition: A conceptual and empirical topography. Journal of Personality and Social Psychology, 82, 112-127. doi:10.1037/0022-3514.82.1.112

Muchinsky, P. M. (2003). Psychology applied to work. Belmont, CA: Wadsworth.

Seligman, M., \& Csikszentmihalyi, M., (2000). Positive psychology: An introduction. American Psychologist, 55, 5-14. doi:10.1037/0003-066X.55.1.5

Wood, A., Froh, J., \& Geraghty, A. (2010). Gratitude and well-being: A review and theoretical integration. Clinical Psychology Review, 30, 890-905. doi:10.1016/j.cpr.2010.03.005 